\title{
Los derechos humanos y la reacción del FMI frente al COVID-19
}

\author{
Human rights and the IMF's Covid-19 response
}

Center for Economic and Social Rights ${ }^{1}$

Revista Derechos en Acción ISSN 2525-1678/ e-ISSN 2525-1686

Año 6/No 18 Verano 2020-2021 (21 diciembre a 20 marzo), 781-788

DOI: https://doi.org/10.24215/25251678e494

Resumen: El Fondo Monetario Internacional tiene un rol importante en la definición de respuestas económicas y de salud pública frente a la pandemia, incluyendo la concesión de subvenciones y préstamos. Hasta ahora, sus acciones distan mucho de lo que requiere una recuperación basada en derechos. Tanto los gobiernos miembros como el propio FMl tienen una serie de obligaciones en materia de derechos humanos, incluso a nivel internacional, que les exigen apoyar esfuerzos de recuperación equitativos a gran escala. Existe una variedad de medidas que el FMI puede tomar en consonancia con sus obligaciones de derechos humanos, incluida la provisión de recursos para promover el gasto público y la eliminación de condicionalidades que restringen la flexibilidad del gobierno.

Abstract: The International Monetary Fund has an important role in defining economic and public health responses to the pandemic, including the provision of grants and loans. So far, its actions fall far short of what a rights-based recovery requires. Both member governments and the IMF itself have a range of human rights obligations, including at the international level, that require them to support large-scale equitable

\footnotetext{
1 Este texto se basa en el informe fue publicado por CESR y Bretton Woods Project en diciembre de 2020 como parte de una serie que resalta cómo podemos aprovechar los compromisos que los gobiernos han asumido para garantizar los derechos humanos, a fin de dirigirnos hacia una recuperación justa de la pandemia de COVID-19. Ver más en: www. cesr.org/covid19
} 
recovery efforts. There are a variety of measures that the IMF can take in line with its human rights obligations, including providing resources to promote public spending and removing conditionalities that restrict government flexibility.

\section{EI FMI y su papel en Argentina, un caso emblemático de una problemática global}

Argentina es un país en el que la sigla FMI no pasa indiferente para sus ciudadanos. El país tiene una compleja historia con el organismo internacional, al punto que las actuaciones de este organismo y sus implicaciones sobre la vida de la gente han sido un tema constante de debate público. El gobierno actual heredó las consecuencias del mayor préstamo concedido a un Estado en toda la historia del FMI, el cual fue adquirido en 2018 después de un largo período en que Argentina había dejado de acudir a las líneas de crédito del Fondo, tras saldar sus deudas con este organismo en 2006.

La falta de transparencia y los términos en que fue negociado el acuerdo de 2018 con el $\mathrm{FMI}^{2}$ motivaron la aprobación reciente por una amplia mayoría parlamentaria de la Ley sobre fortalecimiento de la sostenibilidad de la deuda pública, la cual establece la obligación de contar con un aval parlamentario para la firma de acuerdos sobre la deuda incluyendo, por supuesto, los que se realicen con el FMI. Paralelamente, el gobierno aspira a culminar pronto la renegociación de esa deuda con el FMI, y lograr posteriormente acuerdos con acreedores oficiales agrupados en el Club de París.

La compleja historia del rol del FMI en los países del Sur Global va mucho más allá de Argentina, y descansa en fallas profundas de la arquitectura financiera global. Este texto explora el

2 Al respecto puede consultarse el trabajo de documentación que ha realizado la Coordinadora de Abogados de Interés Público en el sitio web: https://fmiargentina.com/ 
rol de este organismo en el contexto actual y aboga en defensa de una evaluación del papel de este organismo desde una perspectiva de derechos humanos.

\section{¿Por qué es importante este tema en el contexto del COVID-19?}

El Fondo Monetario Internacional (FMI) jugará un papel central ya sea para permitir o para obstaculizar una recuperación económica justa frente a la pandemia de COVID-19. La directora gerente del FMI ha enfatizado en la importancia de promover un mayor gasto público en salud y otros servicios sociales para contener la crisis. Pero, en la práctica, el Fondo no ha hecho lo que predica.

El mandato del FMI tiene repercusiones de gran alcance en los derechos de las personas. El FMI es, en parte, un gestor de crisis. Determina el acceso a la financiación para los países con problemas financieros por la vía de conceder préstamos bajo estrictas condiciones. Pero también ofrece asesoramiento sobre políticas y apoyo técnico a los gobiernos. Esto le da mucha influencia sobre las decisiones de política macroeconómica tomadas por la mayoría de los gobiernos del mundo.

Durante las últimas cuatro décadas, el FMI ha promovido políticas destinadas a reducir la escala del gasto público. Estas políticas han perjudicado la capacidad de los gobiernos para cumplir con los derechos económicos y sociales de los más necesitados. Por ejemplo, en los tres años anteriores a la pandemia de COVID-19, las políticas de austeridad respaldadas por el FMI redujeron el presupuesto de salud de Ecuador en casi un $65 \%$. El país tuvo uno de los brotes más letales y las desigualdades existentes se han agravado.

Se prevé que la actual crisis económica será la peor desde la Gran Depresión. El FMI reconoce que los países del Sur Global tienen una brecha de financiación de 2,5 billones de dólares para financiar la recuperación frente a la pandemia. 
Solo una pequeña parte de dicha brecha ha sido cubierta. Pese a ello, el FMI solamente ha puesto a disposición de sus miembros alrededor de una cuarta parte de su capacidad crediticia, la cual asciende a 1 billón de dólares estadounidenses.

Es preocupante que la austeridad y otras políticas que socavan el cumplimiento de los derechos humanos sigan figurando en el tratamiento que el FMI otorga a la recuperación de la pandemia en el Sur Global. Recientemente, Oxfam demostró que el $84 \%$ de los préstamos COVID-19 del FMI fomentan o exigen austeridad. ${ }^{3}$ En el mismo sentido, Eurodad señaló que al menos 80 países ya se comprometieron con el FMI a implementar severas medidas de austeridad entre 2021 y $2023 .{ }^{4}$

Los países del Norte Global siguen siendo los principales contribuyentes financieros y quienes toman decisiones en el FMI porque la estructura de gobierno de este organismo les otorga una influencia desproporcionada. Por ejemplo, Estados Unidos sigue teniendo poder de veto sobre las decisiones fundamentales y hasta hace poco había bloqueado los esfuerzos para emitir derechos especiales de giro (o DEG), posición que la nueva administración de ese país ha reconsiderado.

\section{¿Qué implican estas obligaciones?}

La mayoría de los gobiernos del mundo han ratificado instrumentos internacionales vinculantes que los comprometen a invertir el máximo de sus recursos disponibles en el cumplimiento de los derechos socioeconómicos de las personas. ${ }^{5}$ Esto incluye

\footnotetext{
3 Ver Nadia Daar y Nona Tamale, A Virus of Austerity? The COVID-19 spending, accountability, and recovery measures agreed between the IMFand your government, OXFAM (2020). Disponible en: https://www.oxfam.org/en/blogs/virus-austerity-covid-19-spending-accountability-andrecovery-measures-agreed-between-imf-and

4 Daniel Munevar, Arrested Development: International Monetary Fund lending and austerity post Covid-19, Eurodad, (2020). Disponible en: https://www.eurodad.org/arrested_development

5 CESR, La Obligación de los Gobiernos de Invertir "el Máximo de los Recursos Disponibles" en Derechos Humanos. Serie Derechos en La Recuperación, núm. 1, (2020a). Disponible en:
} 
el deber de generar ingresos suficientes para invertir en la infraestructura, los bienes y los servicios necesarios para garantizar estos derechos.

Los compromisos de derechos humanos de los gobiernos se extienden más allá de sus fronteras. ${ }^{6}$ Como parte de sus obligaciones extraterritoriales, deben cooperar internacionalmente para ayudar a otros a cumplir con los derechos humanos. Estas obligaciones rigen en una variedad de situaciones. Una es cuando los gobiernos actúan como miembros de organizaciones internacionales que tienen una influencia decisiva sobre la capacidad de otros gobiernos para hacer realidad los derechos humanos. El poder extraordinario del FMI para exigir políticas económicas específicas, como condición de los préstamos necesarios para evitar crisis económicas, lo coloca directamente en esta categoría. Por lo tanto, cuando actúan como miembros del directorio del FMI, los gobiernos deben tomar posiciones que impulsen a la organización a actuar de manera coherente con estas obligaciones de derechos humanos.

Hay varias formas en que el derecho internacional de los derechos humanos también puede aplicarse directamente al FMI. Primero, por tratarse de una agencia especializada de las Naciones Unidas, debe cumplir con las disposiciones de derechos humanos de la Carta de las Naciones Unidas. En segundo lugar, algunos aspectos previstos en los instrumentos de derechos humanos, -en particular en la Declaración Universal de Derechos Humanos (DUDH)—, se han convertido en parte del derecho internacional consuetudinario. Esto significa que son "generalmente aceptados» como de aplicación universal. Por

https://www.cesr.org/es/covid-19-la-serie- \%E2 \%80 \%9Cderechos-en-la-recuperaci \% C3 \%B3n \%E2 \%80 \%9D

6 CESR, La Obligación de los Gobiernos de Cooperar Internacionalmente para Hacer Realidad los Derechos Humanos. Serie Derechos en La Recuperación, No, 1 (2020b). Disponible en: https://www.cesr.org/es/covid-19-la-serie-\%E2\%80\%9Cderechos-en-larecuperaci $\%$ C3\%B3n $\%$ E2\% $80 \% 9 D$ 
lo tanto, la DUDH se aplicaría y obligaría al FMI a efectuar su mandato de conformidad con lo derechos humanos. Por último, se argumenta que su convenio constitutivo (es decir, su estatuto) debe interpretarse en el sentido de que le ordena tener en cuenta las preocupaciones sobre derechos humanos en el desempeño de su mandato.

El alcance de las obligaciones de derechos humanos que se aplican al FMI puede ser más limitado que el de los gobiernos (dado su mandato y poderes más limitados). Pero, como mínimo, es esencial respetar los derechos humanos mediante la adopción de medidas para garantizar que estos no sean vulnerados. Se puede interpretar que esto incluye no interferir con la capacidad de los gobiernos para invertir en derechos, dados los graves daños que tales interferencias pueden causar. Las condiciones de los préstamos que limitan el espacio fiscal, la prescripción de políticas regresivas que no evalúan los impactos sociales y las onerosas cargas de la deuda que aprietan los presupuestos públicos son ejemplos de tal interferencia.

En general, el FMI se ha resistido a la idea de que tiene obligaciones en materia de derechos humanos. Sus directivos han interpretado que su Estatuto les impide considerar factores "políticos» en sus operaciones. Si bien el propósito de este tipo de disposiciones es garantizar que el FMI actúe de manera imparcial con los diferentes gobiernos, con el tiempo estas se han convertido en una excusa para ignorar los impactos que su actividad tiene sobre los derechos humanos.

Aunque el FMI ponga en duda sus obligaciones en materia de derechos humanos, es evidente que sus acciones tienen graves repercusiones sobre los derechos humanos. Teniendo en cuenta que el Fondo se ha atribuido el mérito cuando percibe mejoras en los derechos humanos en el marco de su trabajo, negar las obligaciones correspondientes es políticamente indefendible. 


\section{¿Cómo puede cumplir el FMI con estas obligaciones en su respuesta al COVID-19?}

Se han presentado una serie de propuestas que significarían un paso importante en el cumplimiento de las obligaciones del Fondo en materia de derechos humanos, entre ellas:

- Incrementar urgentemente el apoyo financiero: una emisión a gran escala de Derechos Especiales de Giro crearía de manera efectiva nuevos activos financieros para enfrentar la crisis. ${ }^{7}$ (Ver Tema 4).

- Promover una solución justa y sostenible a la deuda: el FMI debería considerar las obligaciones en derechos humanos en su análisis de sostenibilidad de la deuda, y por consiguiente condonar préstamos insostenibles y apoyar activamente los esfuerzos para establecer un mecanismo de renegociación de la deuda. ${ }^{8}$

- Llevar a cabo evaluaciones de impacto sobre los derechos humanos: el FMI debe identificar sistemáticamente los posibles impactos sobre los derechos humanos de las condiciones de sus préstamos o su asesoría sobre políticas. Esto es particularmente importante para áreas de política como la protección social, los servicios públicos, las reformas salariales y laborales, y las reforma tributarias.

- Eliminar las condiciones crediticias relacionadas con la "consolidación fiscal" o la austeridad: el FMI debe garantizar que todos los préstamos actuales y futuros que sean negociados no impongan metas fiscales restrictivas que puedan socavar la capacidad de los Estados para cumplir con sus obligaciones en derechos humanos.

- Promover políticas que amplíen equitativamente el espacio fiscal: el FMI debería ayudar a los países a hacer que sus

\footnotetext{
7 CESR, Financiamiento vía Deuda para Realizar los Derechos. Serie Derechos en La Recuperación, No, 4, (2020c). Disponible en: https://www.cesr.org/es/covid-19-la-serie$\%$ E2\%80\%9Cderechos-en-la-recuperaci\%C3\%B3n\%E2\%80\%9D 8 Ibid.
} 
sistemas fiscales sean más progresivos y equitativos, combatiendo la evasión y elusión fiscal, y aumentando los impuestos directos, en lugar de promover una dependencia excesiva de los impuestos regresivos al consumo.

- Promover la protección social integral y universal, y la inversión en servicios públicos: el FMI debe hacer un cambio decisivo para alejarse de la promoción de programas de protección social estrechamente focalizados. Cualquier piso de gasto social establecido debe ser compatible con la realización de los derechos humanos y la plena implementación de los pisos de protección social.?

- Reformar las estructuras de gobernanza y toma de decisiones: las acciones anteriores se verán facilitadas por un equilibrio de poder más justo en el FMI. Deben tomarse medidas concretas para reformar las cuotas del FMI y abolir el "pacto de caballeros" sobre el liderazgo del FMI, en consonancia con la meta 10.6 de los ODS.

\section{Preguntas cruciales}

- ¿Qué medidas está impulsando o desestimulando su gobierno dentro del FMI? ¿Qué posiciones está adoptando sobre las propuestas descritas anteriormente?

- ¿Su gobierno recibió financiamiento de emergencia del FMI en 2020? ¿Qué compromisos asumió con el FMI al hacerlo?

- ¿Su gobierno está negociando actualmente un acuerdo de préstamo a más largo plazo con el FMI? ¿Se está consultando a la sociedad civil?

- ¿Ha recibido su país préstamos del FMI en el pasado? ¿Cuáles fueron los impactos sobre los derechos humanos?

9 CESR, Income Support to Protect Rights. Recovering Rights Series. Issue Brief núm. 7 , (2020d). Disponible en: https://www.cesr.org/covid-19-recovering-rights-series-0 